\title{
Quantitative Proteomic Analyses Reveal That Energy Metabolism and Protein Biosynthesis Reinitiation are Responsible for the Initiation of Bolting Induced by High Temperature in Lettuce (Lactuca sativa L.)
}

Jing-hong Hao

Beijing Key Laboratory of New Technology in Agricultural Application

He-Nan Su

Beijing Key Laboratory of New Technology in Agricultural Application

Li-li Zhang

Beijing Key Laboratory of New Technology in Agricultural Application;Yulin Academy of Agricultural

Sciences

Chao-jie Liu

Beijing Key Laboratory of New Technology in Agricultural Application

Ying-yan Han

Beijing Key Laboratory of New Technology in Agricultural Application

Xiao-xiao Qin

Beijing Key Laboratory of New Technology in Agricultural Application

Shuang-xi Fan ( $\square$ fsx20@163.com )

Beijing Key Laboratory of New Technology in Agricultural Application https://orcid.org/0000-00016962-2885

Research article

Keywords: lettuce, high temperature, bolting initiation, proteome, iTRAQ

Posted Date: October 30th, 2020

DOI: https://doi.org/10.21203/rs.3.rs-60101/v1

License: (c) (i) This work is licensed under a Creative Commons Attribution 4.0 International License.

Read Full License 


\section{Abstract \\ Background}

Lettuce (Lactuca sativa L.), one of the most economically important leaf vegetables, exhibits early bolting under high-temperature conditions. Early bolting leads to loss of commodity value and edibility, leading to considerable loss and waste of resources. However, the initiation and molecular mechanism underlying early bolting induced by high temperature remains largely elusive.

\section{Results}

To better understand this phenomenon, the bolting initiation period of lettuce was defined, and a comparative proteomic analysis was conducted in the initiation period of bolting induced by a high temperature $\left(33^{\circ} \mathrm{C}\right)$ and a control temperature $\left(20^{\circ} \mathrm{C}\right)$ using iTRAQ-based proteomics, phenotypic measurement, and biological verification by RT-qPCR. Morphological and microscopic observation showed that the initiation of bolting occurred 8 days after high-temperature treatment. Fructose rapidly accumulated after high-temperature treatment. During bolting initiation, of the 3305 identified proteins, a total of 93 proteins exhibited differential abundances, 38 of which were up-regulated, and 55 were downregulated. Approximately $38 \%$ of the proteins were involved in metabolic pathways and were mainly clustered in energy metabolism and protein synthesis. Furthermore, some proteins involved in sugar synthesis were differentially expressed, which were also associated with energy production.

\section{Conclusions}

This is the first report on the metabolic changes involved in bolting initiation in lettuce. Our study suggested that energy metabolism and ribosomal proteins are pivotal components during bolting initiation. This study could provide a potential regulatory mechanism for the initiation of early bolting by high temperature, which could have applications in the manipulation of lettuce for breeding.

\section{Background}

In the life cycle of flowering plants, bolting is a floral transition involving an important developmental phase switch from vegetative to reproductive growth [1]. After bolting, the floral stems rapidly elongate, and the flower buds begin to differentiate. Early bolting of leafy and root vegetables leads to poor quality of plants and fields, resulting in loss of edibility and commercial value; therefore, it is very important to prevent bolting.

In the progress of bolting, the shoot apical meristem (SAM) elongates and changes into the inflorescence meristem (IM). This phenotype is regulated by the incorporated endogenous and environmental factors, including vernalization, gibberellin (GA), photoperiod, ambient temperature, and autonomous and age- 
related pathways [2, 3]. In Arabidopsis thaliana, many genes were shown to participate in the floral transition. Among the three transcription factors, FLOWERING LOCUS T (FT), SUPPRESSOR OF OVEREXPRESSION OF CONSTANS1 (SOC1) and LEAFY (LFY) act as the main integrators that control the eventual flowering time $[4,5]$.

Previous research on bolting has mostly been conducted on "vernalization"-type plants, such as cabbage $[6,7]$, onion [8], spring cabbage $[9,10]$, and radish $[11,12]$. Based on the genetic mechanism underlying the bolting characteristics of these plants, the identification method, biochemical basis, and molecular mechanism of each level were analysed. Before and after bolting, the physiological and biochemical processes of plants undergo substantial changes, including carbohydrate, soluble protein, and free amino acid metabolism $[13,14]$.

However, there has been little analysis of bolting for "non-low temperature vernalization"-type plants, such as lettuce, and the molecular mechanism remains unclear. Lettuce (Lactuca sativa L.), as a cool-season vegetable, is susceptible to bolting when exposed to supra-optimal temperatures. The optimum growth temperature for lettuce is $15-20^{\circ} \mathrm{C}$, and temperatures greater than $30^{\circ} \mathrm{C}$ promote early bolting, thus affecting the edibility [15]. Therefore, investigation of the molecular mechanism of bolting in lettuce caused by high temperature, inhibition of early bolting, and improvement of yield and quality are important. Currently, two genes, namely, $L S F T$ and $L S S O C 1$, are known to participate in the heat-promoted bolting process $[16,17]$. The expression level of $L s F T$ can be promoted by heat treatment, and knockdown of the expression of this gene in transgenic plants delayed bolting, and the plants failed to respond to high temperatures [16]. LsSOC1 also functions as an activator of bolting during hightemperature treatment [17]. In addition, MADS-box genes and GAs can regulate bolting in lettuce [18]. Overexpression of $L s G A 30 x 1$ may increase the GA1 content to promote early bolting in lettuce [19]. Transcriptomic analysis of lettuce heat treatment was performed and showed the up-regulation of genes implicated in photosynthesis, oxidation-reduction and auxin activity [18]. However, the physiological and molecular basis of bolting initiation were poorly understood.

Proteins are the executors of physiological functions, so the study of protein structure and function can elucidate the changes in mechanism that occur under certain conditions. Therefore, it is necessary to assess the overall changes in intracellular proteins to reveal the mechanisms underlying plant physiological changes. The concept of the proteome was proposed in 1994 by Wilkins and refers to the total proteins expressed in a cell or tissue. Proteomics has been widely used to explore the molecular mechanisms of plant resistance to disease and stress. Proteomic technology has been widely used to explore a variety of physiological and morphological changes associated with plant development and resistance to environmental factors, such as the growth patterns of various stages of fruit development [20], disease resistance [21], heat resistance [22], cold resistance [23], and salt resistance [24, 25]. Currently, iTRAQ (isobaric tags for relative and absolute quantification) is the most popular technology for plant proteomics. 
Here, comparative proteomics has been used to increase our understanding of the mechanism of bolting initiation in lettuce. We examined, for the first time, the global changes in the proteome following bolting initiation using iTRAQ-based proteomic strategies coupled with liquid chromatography-tandem mass spectrometry (LC-MS/MS). The results were verified using real-time quantitative fluorescence PCR, cytological observation and physiological analyses. Our study is expected to identify the proteins or biological processes that participate in bolting initiation caused by high temperature, revealing the molecular mechanism of bolting initiation in "non-low temperature vernalization"-type plants of lettuce and providing a theoretical basis for the regulation of bolting and prevention of premature bolting.

\section{Results}

\subsection{Effect of High Temperature on Bolting of Lettuce}

Bolting of lettuce can be induced by high temperatures [1]. To determine the stage of bolting initiation, we chose the easy bolting variety G-B30 as the test material and set two sets of temperature treatments: high temperature $\left(33 / 25^{\circ} \mathrm{C}\right)$ and control treatment $\left(20 / 13^{\circ} \mathrm{C}\right)$. We found that from the 8th day of hightemperature treatment, the lettuce stem elongation rate was significantly higher than that observed for the control group (Fig. 1A and B). The stem tip in the control group remained conical throughout the entire observational period. The growing point of the stem tip in the high-temperature group remained conical before day 6 . On day 8 , the growing point became larger and less prominent, showing flower bud differentiation starting (Fig. 1C), which is consistent with our previous research results [26].

\subsection{Changes in Sugar Component Levels in Leaf Lettuce During Bolting Induced by High Temperature}

High temperature can lead to severe physiological responses, for example, changes in sugar component levels $[27,28]$. Therefore, we tested the variations in the levels of four main sugar components, namely, galactose, glucose, fructose and sucrose, after high-temperature treatment. We found that the concentrations of galactose and glucose decreased gradually after high temperature treatmentx, while the fructose and sucrose levels increased first and then decreased after treatment. Among these sugar components, fructose production was rapidly induced by high temperature and peaked on the 4th day, exhibiting the opposite trend compared with the control group before the 8th day (Fig. 2). From the 4th day to 8th day after treatment, the levels of all four sugars decreased rapidly and were lowest on the 8th day, while in the control group, all four sugars showed an increasing trend. The lowest concentrations of galactose, glucose, sucrose and fructose on the 8th day after treatment were 3.34, 101.20, 802.01 and $1278.72 \mu \mathrm{g} / \mathrm{g}$, respectively. This result, together with the early bolting of shoots observed after 8 days of high-temperature treatment, showed that the 8th day was an important time point for lettuce bolting induced by high temperature. 
Based on the above changes in phenotypes, cytological observation and physiological analyses after high-temperature treatment, we found that bolting initiation occurs on the 8th day, so we analysed the protein abundance between the control and treatment groups in this period using the iTRAQ-labelled proteomics approach. In total, 3305 proteins were identified (Table S1). The mass spectrometry proteomics data have been deposited to the ProteomeXchange Consortium (http://proteomecentral.proteomexchange.org) via the iProX partner repository with the dataset identifier PXD014464. Each high-confidence protein identification required at least one unique peptide, and quantification required at least two unique peptides. The abundances of total of 93 proteins changed significantly, and 38 of these proteins exhibited increased abundance (blue section in Fig. 3), while 55 proteins exhibited decreased abundance (red section in Fig. 3). Among these proteins, the up-regulated proteins with the highest fold changes were aldehyde dehydrogenase family 2 member B4 (2.32), thaumatin-like protein (2.04) and rRNA 2'-0-methyltransferase fibrillarin-like (2.04). Interestingly, among the upregulated proteins, there were three heat shock protein-like proteins, namely, XP_023757207.1 (1.69), PLY74879.1 (1.50) and XP_023740399.1 (1.39). Detailed information on proteins with differential abundances is provided in Table S2. One GA-related protein 14-like protein was up-regulated by high temperature (1.64). The most highly down-regulated proteins were the TsetseEP-like protein (0.32) and Calvin cycle protein CP12-3 (0.37). All peptide match information, including PSMs, PEP, lonscore, expected value, charge, $\mathrm{MH}+[\mathrm{Da}], \Delta \mathrm{M}[\mathrm{ppm}]$ are provided in Table S3.

\subsection{Functional Classification and Metabolic Pathways of Differentially Abundant Proteins}

To identify the proteins that regulate bolting initiation induced by high temperature, we classified the differentially abundant proteins into 11 functional categories according to the BLAST alignment, GO classification, and literature [29]. GO annotation was performed using Trinotate through a BLAST search against SwissProt to identify the signal changes in BP, MF and CC after high-temperature treatment, and $603 \mathrm{GO}$ terms were annotated. In the BP category, the proteins with differential abundance were annotated with the following terms: metabolic process (38.68\%), cellular process $(28.30 \%)$, response to stimulus $(7.55 \%)$, localization (7.55\%), cellular component organization or biogenesis $(5.66 \%)$, and other terms (12.26\%) (Fig. 4A). The five terms annotated in the MF category were catalytic activity $(54.17 \%)$, binding $(36.11 \%)$, structural molecule activity $(4.17 \%)$, transporter activity $(4.17 \%)$ and molecular function regulator (1.39\%) (Fig. 4B). Similarly, the terms annotated in the CC category were cell $(20.17 \%)$, cell part (20.17\%), membrane (15.97\%), organelle (15.13\%) and macromolecular complex (10.08\%) (Fig. 4C). Next, GO term enrichment analysis of the identified proteins with differential abundances showed that the main GO enrichment functions of the upregulated proteins were organic hydroxy compound biosynthetic process (2); transferase activity, transferring one-carbon groups (2); and methyltransferase activity (2). The main $\mathrm{GO}$ enrichment functions of the down-regulated proteins were proton-transporting V-type ATPase complex (2); proton-transporting V-type ATPase, V1 domain (2); transferase activity, transferring one-carbon groups (2); and methyltransferase activity (2) (Fig. 4D). 
To further identify the proteins with differential abundances that participate in major metabolic and signal transduction pathways, we analysed the proteomic data based on the KEGG database [30]. A total of $107 \mathrm{KEGG}$ signalling/metabolic pathways associated with 46 proteins were extracted. As shown in Fig. 5, the main metabolic pathways were glycolysis/gluconeogenesis (5), protein processing in the endoplasmic reticulum (4), glycerolipid metabolism (3), oxidative phosphorylation (3), pentose and glucuronate interconversions (3), plant-pathogen interaction (3), purine metabolism (3), pyruvate metabolism (3), ribosome (3), histidine metabolism (2), mTOR signalling pathway (2), necroptosis (2), phagosome (2), PI3K-Akt signalling pathway (2), and synaptic vesicle cycle (2).

Glycolysis process, oxidative phosphorylation, pyruvate metabolism, and pentose and glucuronate interconversions are involved in energy metabolism. In the glycolysis process, four proteins with increased abundances were identified, namely, pyruvate decarboxylase 1 like (PD1L), aldehyde dehydrogenase family 2 member B4 (ADF2MB4), pyruvate kinase 1 (PK1), and glyceraldehyde-3phosphate dehydrogenase (G-3-PD), while NADPH-dependent aldo-keto reductase exhibited decreased abundance (Supplementary Fig. 1). In the oxidative phosphorylation pathway, the hypothetical protein LSAT_2 $\times 93901$ was upregulated, while the V-type proton ATPase subunit C-like and V-type proton ATPase catalytic subunit A-like were down-regulated (Supplementary Fig. 2). In pyruvate metabolism, three proteins, namely, the lactoylglutathione lyase GLX1, pyruvate kinase 1 (PK1), and aldehyde dehydrogenase family 2 member B4 (ADF2MB4), were up-regulated (Supplementary Fig. 3). In the pentose and glucuronate interconversions pathway, NADP-dependent D-sorbitol-6-phosphate dehydrogenase-like exhibited increased abundance, while NADPH-dependent aldo-keto reductase and exopolygalacturonase-like exhibited decreased abundance (Supplementary Fig. 4).

In the ribosome, three ribosomal proteins, namely, 40S ribosomal protein S11-2 (40SRPS11-2), 40S ribosomal protein S5-like (40SRPS5I) and 60S ribosomal protein L32-1-like (60SRPL32-1 I), were differentially expressed (Supplementary Fig. 5). In protein processing in the endoplasmic reticulum, the proteins $17.5 \mathrm{kDa}$ class I heat shock protein-like and heat shock protein 83-like were upregulated (Supplementary Fig. 6). These pathways play important roles in protein synthesis.

\subsection{Expression Levels of Genes Encoding Some Identified Proteins}

We further confirmed the changes in protein abundance observed during bolting of lettuce by evaluating the changes in transcript levels and determined the relationship between the abundance of a protein and the level of the corresponding gene transcripts. Ten key node proteins were selected to measure the expression profiles for RT-qPCR analysis. Of the selected proteins, most of the genes showed similar change trends as the iTRAQ results. The mRNA expression trends for seven proteins, including PDIL, G-3PD, lactoylglutathione lyase GLX1, Sorbitol-6-phosphate dehydrogenase (S6PDH), venom phosphodiesterase 2-like, heat shock protein 83-like, 40S ribosomal protein S11-2, were consistent with the protein abundances (Fig. 6). However, the expression levels of three proteins, including exopolygalacturonase-like, S-adenosylmethionine synthase 2-like, Gibberellin-regulated protein 14 
(GASA14) were not consistent with the mRNA and protein levels. Possible reasons for this discrepancy may be post-transcriptional, translational, and post-translational mechanisms or feedback loops between the processes of mRNA translation and protein degradation (Fig. 6).

\section{Discussion}

\subsection{Differentially Expressed Proteins (DEPs) are Involved in Energy Metabolism in the Bolting Process}

During bolting, drastic changes occur in the cell and tissue, which requires substantial energy supply. In the present study, the iTRAQ results showed that most of the pathways included DEPs associated with energy metabolism, mainly the glycolysis process, pyruvate metabolism, and pentose and glucuronate interconversions pathway, and most of these proteins exhibited increased abundances (detailed information is provided in Supplementary Fig. 1). The central role of glycolysis in plants is to provide energy in the form of ATP and to generate precursors such as fatty acids and amino acids for anabolism [31]. In our previous research shows that photosynthesis, carbon metabolism, glycolysis/gluconeogenesis may play an important role in inducing bolting of lettuce [26]. In this study, glycolysis was promoted in bolting plants, it is consistent with the results in Fig. 2, the glucose content was significantly lower than that of the control on the 8 days after high-temperature treatment. In glycolysis, with the expression of glyceraldehyde-3-phosphate dehydrogenase (G-3-PD) increased, the transformation of glycolaldehyde-3p to glycolate-1,3p2 be accelerated. With the increase of pyruvate kinase 1 (PK1) expression, the transformation from phoehoenolpyruvate to pyruvate was also promoted.With the increase of pyruvate decarboxylase 1 like (PD1L) and aldehyde dehydrogenase family 2 member B4 (ADF2MB4) expression and the decrease of alcohol dehydrogenase (AD) expression, pyruvate was finally transformed into acetaldehyde and acetate instead of ethanol. Among these proteins, G-3-PD is the key enzyme in the glycolytic metabolic pathway and is closely associated with energy generation [32]. G-3-PD can catalyse the conversion of glyceraldehyde 3-phosphate to 1,3diphosphoglycerate in glycolysis, and in this oxidation process, energy is generated and stored as ATP. Pyruvate kinase 1 (PK1) has crucial roles in the glycolysis pathway, where this enzyme catalyses the final step of glycolysis. In particular, PK catalyses the transfer of a phosphate group from phosphoenolpyruvate to ADP to yield one molecule of pyruvate and one ATP molecule. The glycolysis pathway facilitates the conversion of glucose to pyruvate, which can be used as a respiratory substrate [33]. Therefore, the amount of pyruvate that entered the TCA cycle increased, and thus, the amount of respiratory substrate increased, thereby accelerating the electron transport chain indirectly, which may have an effect on the process of bolting.

In addition, the protein lactoylglutathione lyase GLX1 in pyruvate metabolism was upregulated during bolting in response to high temperature. Lactoylglutathione lyase GLX1 catalyses the conversion of hemimercaptal, formed from methylglyoxal and glutathione, to S-lactoylglutathione. This protein is involved in step 1 of the subpathway that synthesizes (R)-lactate from methylglyoxal [34]. The glyoxalase 
(GLX) system comprises two enzymes, namely, GLX1 and GLX2, and detoxifies MG; however, this system is poorly understood in the chloroplast compared with the cytosol. In A. thaliana, five GFP-fusion GLXs were present in the chloroplasts. Under high $\mathrm{CO}_{2}$ concentrations, at which increased photosynthesis promotes MG production, GLX1 and GLX2 activities in $A$. thaliana increased, and the expression of AtGLX1-2 and AtGLX2-5 was enhanced. Based on these findings and the phylogeny of GLX in oxygenic phototrophs, the GLX system scavenges MG produced in chloroplasts during photosynthesis [35]. These observations led us to conclude that increased energy production via glycolysis and the pyruvate pathway can be redirected to bolting initiation in lettuce.

\subsection{Fructose May Participate in Early Bolting Induced by High Temperatures in Lettuce}

In all organisms, metabolic processes, including carbohydrates, amino acids, and lipid metabolism, are basic activities and are very sensitive to the environmental factors, such as temperature [36]. In the plant life cycle, bolting is the vital time node between vegetative growth to the reproductive stage, when nutrients are gradually redistributed to the reproductive organs. In lettuce, the SAM rapidly elongates into the floral stem at high temperatures (Fig. 1). According to our data, floral stem growth can be promoted by high-temperature treatment. We found that only fructose rapidly accumulated at high temperature on the 4th day, and the fructose content at high temperature was significantly higher than that in the control group (Fig. 2), while other sugars exhibited no difference in content on the 4th day of heating (Fig. 2). KEGG analysis showed that one protein, an aldehyde reductase, is involved in fructose and mannose metabolism, which is consistent with the above information (Fig. 2). Overall, we speculated that the expression of aldehyde reductase leads to fructose accumulation during the initiation of bolting induced by high temperature. Carbohydrates are not only important components of the cell but also the main source of energy. Therefore, fructose accumulation is also beneficial for increasing energy levels to meet the demand for bolting induced by high temperature.

Carbohydrates play an important role in plant adaptation to high temperature. The accumulation of sugar in plants can regulate the osmotic pressure of cells, enhance the water holding capacity of cells, and ultimately improve their own heat resistance. The researchers found that trehalose can enhance the tolerance of saccharomyces cerevisiae cells to heat [37-38]. Our previous studies also showed that high temperature induced bolting of lettuce was achieved by increasing photosynthesis, carbohydrate metabolism, etc[26]. It was found in this study that the content of fructose and sucrose reached the maximum value on the 4th day after high temperature treatment (Fig. 2). And biological information analysis shows that:Aldehyde reduce (AR) is involved in fructose and mannose metabolism, as well as galactose metabolism. With the increase of its expression, the transformation of D-sorbitol to a-Dglucose, D-galactose to galactitol were accelerated. Ectonucleotide pyrophosphatase/phosphodiesterase family member $1 / 3$ (EPFM1/3) is involved in Starch and sucrose metabolism. With the decrease of its expression, the conversion of UDP glucose to a-d-glucose-1p was inhibited, and the output of glycolysis products was accelerated. Galacturan 1,4-alpha-galacturonidase (G1,4-AG), alcohol dehydrogenase $(\mathrm{NADP}+)(\mathrm{AD}, \mathrm{NADP}+)$, aldehyde reductase $(\mathrm{AR})$ are involved in the pentose and gluconate conversions 
metabolic pathway. Along with the up regulation of $A R$, the down regulation of G1,4-AG and AD,NADP+, accelerate the mutual transformation between pentose and glucuronate. All the results show that carbohydrate plays an important role in plant response to high temperature.

\subsection{DEPs are Preferentially Associated With Protein Synthesis and Amino Acid Metabolism}

Proteins are the basis of all life activities. Protein biosynthesis and amino acid metabolism must be involved in the substantial physiological and structural changes that occur in the cell and tissue during the bolting process. Ribosomes, as the sites of protein synthesis in cells, are one of the ribonucleoprotein particles present in cells and are composed of RNA and ribosomal protein. In ribosomes, amino acids are assembled into protein polypeptide chains based on the instructions encoded by the RNA. Early studies found that many ribosomal proteins are also essential for protein translation. Recently, researchers have found that the ribosome is involved in DNA repair, regulation of cell development and cell differentiation [39]. In plant ribosomal protein mutants, plant growth was inhibited [40]. For example, the 60S acidic ribosomal protein may affect flowering in plants by regulating the translation of flowering-related proteins [41]. In this study, we found that 3 ribosomal proteins, namely, 40S ribosomal protein S11-2 (40SRPS112), 40S ribosomal protein S5-like (40SRPS5I) and 60S ribosomal protein L32-1-like (60SRPL32-1 I), were included among the DEPs (Supplementary Fig. 2). Protein selective degradation is necessary for plant growth and development and a variety of cellular regulatory processes. Proteases can hydrolyse proteins to amino acids and can be divided into endopeptidases and exopeptidases, based on the hydrolysis site of the substrate. We identified five amino acid metabolism-related proteins, involved in histidine metabolism; lysine degradation; beta-alanine metabolism; arginine and proline metabolism; valine, leucine and isoleucine degradation; glycine, serine and threonine metabolism; and cysteine and methionine metabolism. Among them, the down-regulated protein glycine hydroxymethyl transferase promotes glycine, serine and threonine metabolism by inhibiting the transformation of serine to glycine. S-adenosyl methionine synthetase promotes the Cysteine and methionine metabolism by inhibiting the conversion of L-Methionine to S-Adenosyl-L-methionine. Heat shock proteins (HSPs) or molecular chaperones are highly conserved protein families present in all studied organisms. Following cellular stress, the intracellular concentrations of HSPs generally increases several-fold. Hsps undergo ATP-driven conformational changes to stabilize unfolded proteins, unfold these proteins for translocation across membranes or mark these proteins for degradation. HSPs are broadly classified into several families according to molecular weights and functional properties. Extensive studies conducted over the past few decades have suggested that Hsps play a vital role in both normal cellular homeostasis and stress response. Hsps have been reported to interact with numerous substrates and are involved in many biological functions, such as cellular communication, immune response, protein transport, apoptosis, cell cycle regulation, gametogenesis and ageing $[42,43]$. All the data confirmed that many proteins involved in protein synthesis and amino acid metabolism were involved in physiological and morphological changes during the early bolting induced by high temperature.

\section{Conclusion}


According to phenotypic and cytological observations, we found that the initiation of bolting occurred 8 days after high-temperature treatment at $33^{\circ} \mathrm{C}$, with no bolting occurring at a normal temperature of $20^{\circ} \mathrm{C}$. To obtain further insights into the mechanism responsible for bolting initiation, this study presents, for the first time, a comprehensive analysis of lettuce quantitative proteomics during bolting initiation. During the initiation of bolting in lettuce, energy production appears to be enhanced, or at least poised for enhancement. Energy metabolism can regulate gene expression (protein biosynthesis reinitiation). These cellular responses are responsible for the occurrence of flower bud differentiation and cell elongation in plants, thereby inducing bolting. The data set indicates that a complete understanding of the biochemical and physiological changes during bolting initiation is possible for lettuce.

\section{Materials And Methods}

\subsection{Plant materials and treatment}

Leafy lettuce (Lactuca sativa L.) GB-30 (bolting resistant, numbered and conserved in our laboratory) was considered as experiment material. The seeds were sown in a sand/soil/peat (1:1:1 v/v) mixture and grown in the Beijing University of Agriculture Experimental Station in Beijing under standard greenhouse conditions (14 $\mathrm{h}$ light; $300-1300 / \mathrm{mol} /\left(\mathrm{m}^{2} \mathrm{~s}\right) ; 20 \pm 2{ }^{\circ} \mathrm{C}$ during the day; $13 \pm 2{ }^{\circ} \mathrm{C}$ at night; $10 \mathrm{~h}$ dark; and $50-70 \%$ relative humidity). Pest control and water management were performed according to standard practices. When the sixth true leaves were formed, the lettuce plants were moved to a growth chamber under the following conditions: temperature of $20 / 13^{\circ} \mathrm{C}$ (day/night), a $14 / 10 \mathrm{~h}$ photoperiod, and $60 \%$ relative humidity for two days of acclimatization. Then, the plants were divided into two groups. The control group was kept under the standard greenhouse conditions as described above. The other group was moved to another growth chamber and treated with high temperatures of 33 and $25^{\circ} \mathrm{C}$ during the day and night, respectively. The other environmental conditions were unchanged.

The blossom buds were observed every two days by stereomicroscopy and paraffin-based methods [44] to monitor the progress of flower bud differentiation. The stem lengths (in $\mathrm{cm}$ ) of the control and treatment plants were measured every four days using a ruler. Simultaneously, stem samples from the control and treatment plants were collected, frozen in liquid nitrogen, and stored at $-80^{\circ} \mathrm{C}$ for further physiological analysis. On day 8 , stem samples from the control and treatment plants were collected, frozen in liquid nitrogen, and stored at $-80^{\circ} \mathrm{C}$ for further proteome analysis.

\subsection{Measurement of Sugar Components}

Approximately $0.2 \mathrm{~g}$ samples were ground in $10 \mathrm{~mL} 80 \%(\mathrm{v} / \mathrm{v})$ ethanol in a tube, and then the tube was placed in a boiling water bath for $1 \mathrm{~h}$, cooled, and centrifuged at $1,000 \mathrm{~g}$ for $10 \mathrm{~min}$. The pellet was extracted two additional times with $10 \mathrm{~mL} 80 \%(\mathrm{v} / \mathrm{v})$ ethanol. The supernatants from each extraction were combined and evaporated to dryness in a boiling water bath. The samples were resolubilized in $0.5 \mathrm{~mL}$ distilled water and filtered through an acetate filter $(0.45 \mu \mathrm{m}$ pore size, Nalgene, Thermo Fisher Scientific, Waltham, MA). 
The contents of galactose, glucose, fructose, sucrose were determined using the method of high performance liquid chromatography (HPLC) [45]. The system included a Waters 6000A pump (Millipore, Waters Chromatography Division, Milford, MA), an Inertsil NH2 column (250 mm × $4.6 \mathrm{~mm}, 5 \mu \mathrm{m}$, Dikma Company, Forest Lake, CA) and a Waters 2410 refractive index detector connected to a strip chart recorder. Distilled water, at a flow rate of $10 \mathrm{~mL} / \mathrm{min}$, was used as the solvent of the $70 \%(\mathrm{v} / \mathrm{v})$ acetonitrile. The column temperature was maintained at $35^{\circ} \mathrm{C}$ and was preceded by a Waters Bondapak C18/Corasil guard and a set of anion and cation cartridges (deashing guards, Bio-Rad Laboratories, Richmond, CA). All guards were operated at an ambient temperature of $25^{\circ} \mathrm{C}$, and $20 \mu \mathrm{L}$ samples were injected. The galactose, glucose, fructose, sucrose were identified and quantified from the retention times and the peak heights of stachyose and raffinose standards. All of chemicals were of chromatographical grade in purity. The standards of stachyose and raffinose were purchased from Sigma (St. Louis City, $\mathrm{MO})$.

\subsection{Protein Extraction}

The samples were extracted using the trichloroacetic acid (TCA)/acetone method as previously described with some modifications. Approximately $2.5 \mathrm{~g}$ of each sample was ground into a fine powder in liquid nitrogen. The powder was resuspended in $30 \mathrm{~mL}$ of $10 \%(\mathrm{w} / \mathrm{v})$ trichloroacetic TCA/acetone $(65 \mathrm{mM}$ dithiothreitol (DTT)) in a $50-\mathrm{mL}$ tube. The mixture was stored overnight (minimum duration) at $-20^{\circ} \mathrm{C}$ for precipitation. After centrifugation at $10,000 \mathrm{rpm}$ for $30 \mathrm{~min}$ at $4{ }^{\circ} \mathrm{C}$, the supernatant was discarded. Subsequently, $40 \mathrm{~mL}$ of pre-cooled acetone was added, and the mixture was centrifuged at $7000 \mathrm{rpm}$ for $15 \mathrm{~min}$. This supernatant was also discarded, and the pellet was washed three times with acetone. Then, $200 \mu \mathrm{L}$ of lysis buffer (SDT buffer (4\% (v/v) SDS, $100 \mathrm{mM}$ Tris-HCl, $1 \mathrm{mM}$ DTT, pH 7.6)) was added to the precipitate, and the mixture was placed on ice for $20 \mathrm{~min}$ after ultrasonic treatment for $30 \mathrm{~min}$. After centrifugation at $12,000 \mathrm{rpm}$ for $10 \mathrm{~min}$ at $4{ }^{\circ} \mathrm{C}$, the supernatant was extracted. The precipitate was vacuum-dried. The total protein in the supernatant was quantified using the BCA Protein Assay Kit (BioRad, Hercules, CA, USA).

\subsection{Protein Digestion and ITRAQ Labelling}

Protein digestion was performed according to the FASP procedure described by Wi'sniewski and colleagues[46], and the resulting peptide mixture was labelled using the 8-plex ITRAQ reagent according to the manufacturer's instructions (Applied Biosystems, Foster City, CA, USA). In brief, each 200- $\mu$ g protein sample was incorporated into $30 \mu \mathrm{L}$ of SDT buffer (4\% (v/v) SDS, $100 \mathrm{mM} \mathrm{DTT}, 150 \mathrm{mM}$ Tris-HCl, pH 8.0). The detergent, DTT, and other low-molecular-weight components were removed using UA buffer (8 M urea, $150 \mathrm{mM}$ Tris-HCl, $\mathrm{pH}$ 8.0) and repeated ultrafiltration (Microcon units, $30 \mathrm{kDa}$ ). Then, $100 \mu \mathrm{L}$ of $0.05 \mathrm{M}$ iodoacetamide in UA buffer was added to block reduced cysteine residues, and the samples were incubated in the dark for $20 \mathrm{~min}$. The filters were washed three times with $100 \mu \mathrm{L}$ UA buffer and, subsequently, twice with $100 \mu \mathrm{L}$ of DS buffer ( $50 \mathrm{mM}$ triethylammonium bicarbonate at $\mathrm{pH}$ 8.5). Finally, the protein suspensions were digested at $37^{\circ} \mathrm{C}$ overnight using $2 \mu \mathrm{g}$ of trypsin (Promega, Madison, WI, USA) in $40 \mu \mathrm{L}$ of DS buffer, and the resulting peptides were collected as a filtrate. The peptide content was estimated by measuring the UV spectral density at $280 \mathrm{~nm}$ using an extinction coefficient of 1.1 for a 
$0.1 \%(\mathrm{~g} / \mathrm{L})$ solution, which was calculated based on the frequency of tryptophan and tyrosine in vertebrate proteins. For labelling, each iTRAQ reagent was dissolved in $70 \mu \mathrm{L}$ of ethanol and added to the corresponding peptide mixture. The experiment was performed in three independent biological replicates, each of which consisted of a pool of three plants. The three independent biological replications of the control were labelled (CK1)-113, (CK2)-114, and (CK3)-115, and the three independent biological replications of the treatment were labelled $(\mathrm{H} 1)-116,(\mathrm{H} 2)-117$, and $(\mathrm{H} 3)-118$.

\subsection{Peptide Fractionation with Strong Cation Exchange (SCX) Chromatography}

The iTRAQ-labelled peptides were fractionated by strong cation exchange (SCX) chromatography using an AKTA Purifier system (GE Healthcare, Chicago, IL, USA). The dried peptide mixture was reconstituted and acidified with $2 \mathrm{~mL}$ of buffer A (10 mM KH2PO4 in 25\% (v/v) acetonitrile (ACN), pH 2.7) and loaded onto a PolySULFOETHYL $4.6 \times 100$ mm column $(5 \mu \mathrm{m}, 200 \AA$, PolyLC Inc., Columbia, MD, USA). The peptides were eluted with buffer $\mathrm{B}(500 \mathrm{mM} \mathrm{KCl}, 10 \mathrm{mM} \mathrm{KH} 2 \mathrm{PO} 4$ in $25 \%(\mathrm{v} / \mathrm{v}) \mathrm{ACN}, \mathrm{pH} 2.7)$ at a flow rate of $1 \mathrm{~mL} / \mathrm{min}$ with the following gradient: $0-8 \%$ buffer $\mathrm{B}(500 \mathrm{mM} \mathrm{KCl}, 10 \mathrm{mM} \mathrm{KH} 2 \mathrm{PO} 4$ in $25 \% \mathrm{ACN}, \mathrm{pH}$ 3.0) for $22 \mathrm{~min}, 8-52 \%$ buffer B from 22-47 min, 52-100\% buffer B from 47-50 min, 100\% buffer B from 50-58 min. Then, after $58 \mathrm{~min}$, buffer $B$ was reset to $0 \%$. The elution was monitored by measuring the absorbance at $214 \mathrm{~nm}$, and fractions were collected every minute. The collected fractions were combined into 15 fractions and desalted on $\mathrm{C} 18$ cartridges (Empore ${ }^{\mathrm{TM}}$ SPE C18 cartridges (standard density), bed inner diameter (I. D.) $7 \mathrm{~mm}$, volume $3 \mathrm{~mL}$; Sigma, St. Louis, MI, USA). Each fraction was concentrated by vacuum centrifugation and reconstituted in $40 \mu \mathrm{L}$ of $0.1 \%(\mathrm{v} / \mathrm{v})$ acetic acid. All samples were stored at $-80^{\circ} \mathrm{C}$ until LC-MS/MS analysis.

\subsection{Liquid Chromatography (LC)-Electrospray lonization (ESI) Tandem Mass Spectrometry (MS/MS) Analysis}

Experiments were performed on a Q-Exactive mass spectrometer coupled with an Easy nLC (Proxeon Biosystems, now Thermo Fisher Scientific). Into each fraction, $10 \mu \mathrm{L}$ was injected for nano LC-MS/MS analysis. The peptide mixture $(1-2 \mu \mathrm{g})$ was loaded onto a C18 reversed-phase column (Thermo Scientific Easy Column, $10 \mathrm{~cm}$ length, $75 \mu \mathrm{m}$ I. D., $3 \mu \mathrm{m}$ resin) in buffer $A(0.1 \%(\mathrm{v} / \mathrm{v})$ formic acid) and separated with a linear gradient of buffer $B(80 \%(v / v)$ acetonitrile and $0.1 \%(v / v)$ formic acid) at a flow rate of $250 \mathrm{~nL} / \mathrm{min}$, controlled by IntelliFlow technology, for $140 \mathrm{~min}$. MS data were acquired using a datadependent top 10 method, which dynamically chooses the most abundant precursor ions from the survey scan $(300-1800 \mathrm{~m} / \mathrm{z})$ for HCD fragmentation. Determination of the target value is based on predictive automatic gain control (pAGC). The dynamic exclusion duration was $60 \mathrm{~s}$. Survey scans were acquired at a resolution of 70,000 at $\mathrm{m} / \mathrm{z} 200$, and the resolution for the HCD spectra was set to 17,500 at m/z 200 . The normalized collision energy was $30 \mathrm{eV}$, and the underfill ratio, which specifies the minimum percentage of the target value likely to be reached at the maximum fill time, was defined as $0.1 \%$. The instrument was run with peptide recognition mode enabled.

\subsection{Database Search and Protein Quantification}


MS/MS spectra were searched using the MASCOT engine (Matrix Science, London, UK; version 2.2) embedded into Proteome Discoverer 1.3 (Thermo Electron, San Jose, CA, USA) against

Lactuca.Unigene.pep.fasta (a lettuce protein database translated from the transcriptome, created by our laboratory, which has 53,584 entries in total. The material here was G-B30, which is consistent with the variety studied in this experiment.). For protein identification, the following settings were used: peptide mass tolerance $=20 \mathrm{ppm} ; \mathrm{MS} / \mathrm{MS}$ tolerance $=0.1 \mathrm{Da}$; enzyme $=$ trypsin; max missed cleavage $=2 ;$ fixed modification: carbamidomethyl (C), iTRAQ 8-plex (K), iTRAQ 8-plex (N-term); variable modification: oxidation (M), iTRAQ 8-plex $(Y)$. The false discovery rate (FDR) of protein identification was $\leq 0.01$. At least one unique peptide was involved in the identification of every high-confidence protein.

The relative quantification of proteins was based on the signal intensity of the reporter ion, which reflects the relative abundance of the peptide. The protein ratio (fold change) was obtained according to different comparison groups (high-temperature treatment/control) through the ratio of reporter ions labelled with different isotopes as described above. For differentially expressed proteins (DEPs), one can use a protein containing at least two unique spectra, and only these unique spectra, for quantification. Only fold changes $\geq 1.20$ or $\leq 0.83$ (the ratios with $p$-values $<0.05$ and expected cutoff values $<0.05$ with $95 \%$ confidence) were considered significant. Median intensities were used for normalization, and outliers were removed automatically (the quantitative protein ratio was normalized by the median ratio in MASCOT).

\subsection{Bioinformatic Analysis of Proteins}

Functional category analysis was performed with Blast2GO software (http://www.geneontology. org) [47]. The online Kyoto Encyclopedia of Genes and Genomes (KEGG) database (http://www. genome.jp/kegg/) was used to retrieve KEGG Orthology (KO) data, and the data were subsequently mapped on pathways in the KEGG database [48]. The corresponding KEGG pathways were extracted. To further explore the impact of proteins with differential abundances in cell physiological processes and to identify internal associations between proteins with differential abundances, enrichment analysis was performed. Gene Ontology (GO) enrichment analysis was performed for three ontologies (biological process (BP), molecular function (MF), and cellular component(CC)). The Benjamini-Hochberg correction for multiple testing was further applied to adjust the derived $\mathrm{p}$-values. Only functional categories and pathways with $p$-values $<0.05$ were considered significant.

\subsection{Total RNA Extraction and RT-qPCR Analysis}

Transcript levels of genes associated with DEPs were determined using real-time quantitative polymerase chain reaction (RT-qPCR). For total RNA extraction, stems were extracted using an RNA Rapid Extraction Kit (Aidlab Biotech, Beijing, China) according to the manufacturer's instructions. A Reverse Aid First Strand cDNA Synthesis Kit (TaKaRa Biotech, Beijing, China) was used for reverse transcribing RNA to cDNA. The procedure was as follows: RNA $(2 \mu \mathrm{g})$ mixed with $1 \mu \mathrm{L}$ Oligo $\mathrm{d}(\mathrm{T}) 18(0.5 \mu \mathrm{g} / \mu \mathrm{L}), 2 \times \mathrm{TS}$ Reaction Mix $(10 \mu \mathrm{L})$ and, TransScript RT/RI Enzyme Mix $(1 \mu \mathrm{L})$ with an additional $20 \mu \mathrm{L}$ of RNase-free Water. The mixture was mixed gently and incubated at $42{ }^{\circ} \mathrm{C}$ for $15 \mathrm{~min}$. The reaction was terminated by 
incubation at $85^{\circ} \mathrm{C}$ for $5 \mathrm{~s}$, and the cDNAs of the product were stored at $-20^{\circ} \mathrm{C}$. The cDNA samples were used as a template, then mixed with $200 \mathrm{nmol}$ primer and SYBR Green PCR Real Master Mix (Takara, Kusatsu, Japan) for real-time PCR analysis using Bio-Rad CFX 96 real-time PCR instruments and CFX manager software ver 3.0 (Bio-Rad laboratories, California, USA). The temperature procedure was as follows: 3 min at $95^{\circ} \mathrm{C}$, and 40 cycles of denaturation at $95^{\circ} \mathrm{C}$ for $20 \mathrm{~s}$, annealing at $59{ }^{\circ} \mathrm{C}$ for $20 \mathrm{~s}$, and extension at $72^{\circ} \mathrm{C}$ for $20 \mathrm{~s}$. The $18 \mathrm{~S}$ sequence was used as an internal standard for normalization.

\subsection{Statistical Analysis}

All tests were performed in triplicate. For measurement of stem length, each biological replicate had six samples from six plants. For observation of flower bud differentiation, each biological replicate had five samples from six plants. For physiological and proteomic analyses, three different stems were pooled as one biological sample, which was performed three times to produce three independent biological replicates (of three pooled stems) for both physiological and proteomic analyses. The presented data represent the means \pm SDs of three replications and were statistically analysed using analysis of variance (ANOVA) with SPSS 10.0 (International Business Machine, Chicago, IL, USA). Tukey's test was used to identify significant differences among groups $(p<0.05, p<0.01)$. Figures representing the physiological parameters were generated using Origin Pro 8.0 SR4 (Origin Lab, Northampton, MA, USA) and Microsoft Office PowerPoint 2007.

\section{Declarations}

\section{Ethics approval and consent to participate}

Not applicable.

\section{Consent for publication}

Not applicable.

\section{Availability of data and materials}

The following are available online at www.mdpi.com/link. Table S1: All proteins identified using iTRAQ in lettuce stems during bolting initiation induced by high temperature, Table S2: The differentially expressed proteins in lettuce stem during bolting initiation induced by high temperature, Table S3: All Peptides Identified Using iTRAQ in Lettuce stems during bolting initiation induced by high temperature.

\section{Competing interests}

The authors declare that they have no competing interests

\section{Funding}


This work was financially supported by the 2018 Joint Funding Project of Beijing Natural Science Foundation-the Municipal Education Commission (KZ201810020027), the National Natural Science Foundation of China (grant no. 3197240), the 2019 Agriculture Education Teaching Reform Project of Beijing University of Agriculture (BUA2019JG), and Beijing Leafy Vegetables Innovation Team of Modern Agro-industry Technology Research System (BAIC07-2020). We are grateful to Rui Yan and Jie Kang from Shanghai Applied Protein Technology for proteomic and bioinformatics analysis.

\section{Authors' contributions}

J.H., H.S., L.Z. and S.F. conceived and designed the experiments. J.H., H.S and L.Z. performed the experiments. C.L. performed the data analysis and prepared the figures and tables. Y.H. advised on the analysis and interpretation of protein data. X. Q. prepared the figures and tables. J.H., H.S. and L.Z. wrote the paper. All authors read and approved the final manuscript.

\section{Acknowledgements}

Not applicable.

\section{References}

1. Fukuda, M.; Matsuo, S.; Kikuchi, K.; Honda, I. The endogenous level of GA1 is upregulated by high temperature during stem elongation in lettuce through LsGA3ox1 expression. Plant Physiol.2009, $166,2077-2084$.

2. Komeda, Y., Genetic regulation of time to flower in Arabidopsis thaliana. Rev. Plant Biol. 2004, 55, 521-535.

3. Srikanth, A.; Schmid, M., Regulation of flowering time: all roads lead to Rome. Mol. Life Sci. 2011, 2013-2037.

4. Parcy, F., Flowering: a time for integration. j. develop. Biol. 2005, 49, 585-593.

5. Balasubramanian, S.; Sureshkumar, S.; Lempe, J.; et al. Potent Induction of Arabidopsis thaliana Flowering by Elevated Growth Temperature. PLoS Genetics2006, 2, e106.

6. Kitamoto, Naoko.; Yui, Susumu.; Nishikawa, Kazuhiro.; Takahata, Yoshihito.; Yokoi, Shuji, A naturally occurring long insertion in the first intron in the Brassica rapaFLC2 gene causes delayed bolting. Euphytica2014, 196, 213-223.

7. Ji, X.H.; Zhang, L.; Lu, X.X.; Liu, Y.T.; Wang, Y.G., Inheritance Analysis of Bolting Associated Traits Using Mixed Major Gene Plus Polygene Model in Brassica rapa. Agricultural Biotechnology2013, 2, 26-30.

8. Yamasaki, A.; Miura, H.; Tanaka, K., Effect of photoperiods before, during and after vernalization on flower initiation and development and its varietal difference in Japanese bunching onion (allium fistulosum). J. Horti. Sci. Biotech. 2000, 6, 645-650. 
9. Andrzej, K.; Stanislaw, C.; Piotr, S.; Aneta, G.; Gil, J., Effects of Row Covers Using Non-woven Fleece on the Yields, Rate of Bolting, and Quality of Heading Chinese Cabbage in Early Spring Cultivation. Journal of the Japanese Society for Horticultural Science2014, 2, 133-139.

10. Jian, J.M.; Yan J.R.; Li, Y.Y., Effects of Spray Application of Lanthanum and Cerium on Yield and Quality of Chinese Cabbage (Brassica chinensis L) Based on Different Seasons. Biol Trace Elem Res2014, 3, 427-432.

11. Yuko, Y.; Noboru, T.; Yasunori, K., Isolation and Identification of an Anti-Bolting Compound, Hexadecatrienoic Acid Monoglyceride, Responsible for Inhibition of Bolting and Maintenance of the Leaf Rosette in Radish Plants. Plant \& cell physiology 2010, 8, 1341-1349.

12. Lim, S.H.; Song, J.H.; Kim, D.H.; Kim, J.; Lee, J.Y.; Kim, Y.M.; Ha, S.H., Activation of anthocyanin biosynthesis by expression of the radish R2R3-MYB transcription factor gene RsMYB1. Plant Cell Reports 2016, 3, 641-653.

13. Dong, Y.X.; Cheng, Z.H.; Meng, H.W., The effect of cultivar sowing date and transplant location in field on bolting of Welsh onion (Allium fistulosum). Bmc Plant Biology2013, 13, 154-160.

14. Pulkrábek, J.; Svachula, V.; Urban, J., Regulation of Bolting and Flowering in Sugar Beet. Listy Cukrovarnické a Reparské2015, 1, 25-29.

15. Jenni, S.; Yan, W., Genotype by environment interactions of heat stress disorder resistance in crisphead lettuce. Plant Breeding 2009, 8, 374-

16. Chen, Z.; Han, Y.; Ning, K.; Ding, Y.; Zhao, W.; Yan, S.S.; Luo, C.; Jiang, X.T.; Fe, D.F.; Liu, R.Y.; Wang, Q.; Zhang, X.L., Inflorescence Development and the Role of LsFT in Regulating Bolting in Lettuce (Lactuca sativa). Frontiers in Plant Science2018a, 8, 359-364.

17. Chen, Z.; Zhao, W.S.; Fe, D.F.; Han, Y.Y.; Ning, K.; Luo, C.; Wang, S.L.; Liu, R.Y.; Zhang, X.L.; Wang, Q., LCM-seq reveals the crucial role of LsSOC1 in heat-promoted bolting of lettuce (Lactuca sativa). The Plant Journal 2018b, 95, 516-528.

18. Han, Y.Y.; Chen, Z.J.; Lu, S.S.; et al. MADS-Box Genes and Gibberellins Regulate Bolting in Lettuce (Lactuca sativa). Frontiers in Plant Science 2016, 7.

19. Fukuda, M.; Matsuo, S.; Kikuchi, K.; Mitsuhashi, W.; Toyomasu, T., Honda, I., Gibberellin Metabolism during Stem Elongation Stimulated by High Temperature in Lettuce. Acta Horticulturae2012, 932,259 [

20. Qi, X.G.; Xiu, G.; Zhao, S.L.; Gu, H., Advance of proteomics in the research of fruit tree reproduction. Journal of Fruit Science 2012, 29, 1115-1120.

21. Yang, Y.H.; Dai, L.X.; Zhu, H.C.; Liu, K.M.; Xiao, Y., Comparative proteomic analysis of rice stripe virus (RSV)-resistant and-susceptible rice cultivars. Australian Journal of Crop Science2013, 4, 588-593.

22. Rollins, J.A.; Habte, E.; Templer, S.E.; Colby, T.; Schmidt, J., Leaf proteome alterations in the context of physiological and morphological responses to drought and heat stress in barley (Hordeum vulgare). Journal of Experimental Botany 2013, 11, 3201-3212.

23. Wu, F.Z.; Wang, B.C.; Yang, C.P., Proteomic analysis of the cold stress response in the leaves of birch (Betula platyphylla Suk). Plant Omics 2014, 4, 195-204. 
24. Evers, D.; Legay, S.; Lamoureux, D.; Hausman, J.F.; Hoffmann, L., Towards a synthetic view of potato cold and salt stress response by transcriptomic and proteomic analyses. Plant Molecular Biology2012, 4, 503-514.

25. Fan, H.F.; Xu, Y.L.; Du, C.X.; Wu, X., Phloem sap proteome studied by iTRAQ provides integrated insight into salinity response mechanisms in cucumber plants. Journal of Proteomics2015, 12, 54-67.

26. Hao,J.H.; Zhang, L.L.; Sun, Y.C.; Li,P.P.; Li,J.K.; Wang,L.; Qi,Z.Y.; Li,B.Y.; Liu,W.H.; Han,Y.Y.; Liu,C.J.; Fan,S.X., Quantitative Proteomic Analysis of Lettuce (Lactuca sativa L.) Reveals Molecular Basis Associated Auxin, Gibberellin, and Photosynthesis With Bolting Induced by High Temperature,frontiers in plant science, 2018, 19(10), 2967.

27. Anne-Sophie, M.; Charlotte, T.; Dailly Hélène; et al. Impact of high temperature on sucrose translocation, sugar content and inulin yield in Cichorium intybus var. sativum. Plant and Soil 2018, 432 (1-2): 273-288.

28. Islam, Md. ; Baohua, Feng, B.H.; Chen, T.T.; Fu, W.M.; Zhang, C.X.. Abscisic acid prevents pollen abortion under high-temperature stress by mediating sugar metabolism in rice spikelets. Physiologia plantarum2019, 165 (3): 644-663.

29. Li, L.Q.; Zhang, Y.; Zou, L.Y.; Li, C.Q.; Yu, B.; Zheng, X.Q.; Zhou, Y., An Ensemble Classifier for Eukaryotic Protein Subcellular Location Prediction Using Gene Ontology Categories and Amino Acid Hydrophobicity. PLOS ONE2012, 7, e31057.

30. Zi, J.; Zhang, J.Y.; Wang, Q.H.; Zhou, B.J.; Zhong, J.Y., Stress Responsive Proteins Are Actively Regulated during Rice (Oryza sativa) Embryogenesis as Indicated by Quantitative Proteomics Analysis. PLoS One2013, 9, 1-10.

31. Shi, H.T.; Ye, T.; Chan, Comparative proteomic responses of two bermudagrass (Cynodon dactylon (L). Pers.) varieties contrasting in drought stress resistance. Plant Physiology and Biochemistry2014, $82,218-228$.

32. Qvit, N.; Joshi, A.U.; Cunningham, A.D.; et al. Glyceraldehyde-3-Phosphate Dehydrogenase (GAPDH) Protein-Protein Interaction Inhibitor Reveals a Non-catalytic Role for GAPDH Oligomerization in Cell Death. Journal of Biological Chemistry 2016, 291, 13608.

33. Giege, P.; Heazlewood, J.L.; Roessner-Tunali, U.; Millar, A.H.; Fernie, A.R.; Leaver, C.J.; Sweetlove, L.J., Enzymes of glycolysis are functionally associated with the mitochondrion in Arabidopsis cells. Plant Cell 2003, 15, 2140-

34. Tabata $S$, Kaneko T, Nakamura $Y$, et al. Sequence and analysis of chromosome 5 of the plant Arabidopsis thaliana. Nature, 2000, 408, 820-822.

35. Shimakawa G, Ifuku K, Suzuki Y, Makino A, et al. Responses of the chloroplast glyoxalase system to high CO2 concentrations. Biosci Biotechnol 2018, 82, 2072-2083.

36. Hamada, A.M., Alteration in growth and some relevant metabolic processes of broad bean plants during extreme temperatures exposure. Acta Physiologiae Plantarum 2001, 23, 193-200.

37. Plourde-owobi L.Dumer s. Coma G, et al. Trehalose reserve in Saccharomyces cerevisiae phenomenon of transport, accumulation and role in cell viability [J]. International Journal of Food 
Microbiology,2000,55(1):33-40

38. De Virgilio $\mathrm{C}$, Hottiger T, Dominguez $\mathrm{J}$, et al. The role of trehalose synthesis for the acquisition of

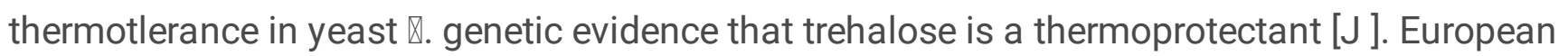
Journal of Biochemistry, 1994, 219 (2):179-186

39. Byrne, M.E., A role for the ribosome in development. Cell Press. 2009, 6, 512-519.

40. Zhan, J.H.; Cui, Z.M., Research Advances on ribosomal protein 55 (RPS5) gene. Frontier research, 2007, 213, 19-21.

41. Gu, Z.M.; Wang, J.F.; Huang, J., Molecular Cloning and Sequence Analyzing of Cytoplasmic Ribosomal Protein GeneOsRPS7 from Rice (Oryza sativa). Hereditas, 2004, 2, 181-185.

42. Surajit S.; Singh D.; Yadav R.; et al. Heat shock proteins: Molecules with assorted functions. Frontiers in Biology,2011, 6, 312-327.

43. Park, C.J.; Seo, Y., Heat shock proteins: a review of the molecular chaperones for plant immunity. Plant Pathology Journa/2015, 31, 323-333.

44. Zhang, S.; Zhang, Y.X.; Cao, Y.C.; Lei, Y.B.; Jiang, H., Quantitative Proteomic Analysis Reveals Populus cathayana Females Are More Sensitive and Respond More Sophisticatedly to Iron Deficiency than Males. Proteome Res.2016, 15, 840-850.

45. Reynolds ES. The use of lead citrate at high $\mathrm{pH}$ as an electron-opaque stain in electron microscopy. Cell Biol. 1963; 17: 208-

46. Wis'niewski, J.R.; Zougman, A.; Nagaraj, N.; Mann, M., Universal sample preparation method for proteome analysis. Methods2009, 6, 359-362.

47. Conesa, A.; Götz, S.; García-Gómez, J.M.; Terol, J.; Talón, M.; Robles, M., Blast2GO: A universal tool for annotation, visualization and analysis in functional genomics research. Bioinformatics2005, 21, 3674-3676.

48. Moriya, Y.; Itoh, M.; Okuda, S.; Yoshizawa, A.C.; Kanehisa, M., KAAS: An automatic genome annotation and pathway reconstruction server. Nucleic Acids Res. 2007, 35, 182-185.

\section{Supplemental Material}

\section{Supplemental Figures:}

Supplemental Figure S1: Maps of typical metabolism (energy metabolism) pathways.

Supplemental Figure S2: Maps of typical metabolism (protein synthesis) pathways.

\section{Supplemental Tables:}

Supplemental Table S1: All proteins identified using iTRAQ in lettuce stems during bolting initiation induced by high temperature 
Supplemental Table S2: The differentially expressed proteins in lettuce stem during bolting initiation induced by high temperature

Supplemental Table S3: All peptides identified using iTRAQ in lettuce stems during bolting initiation induced by high temperature

\section{Figures}


A
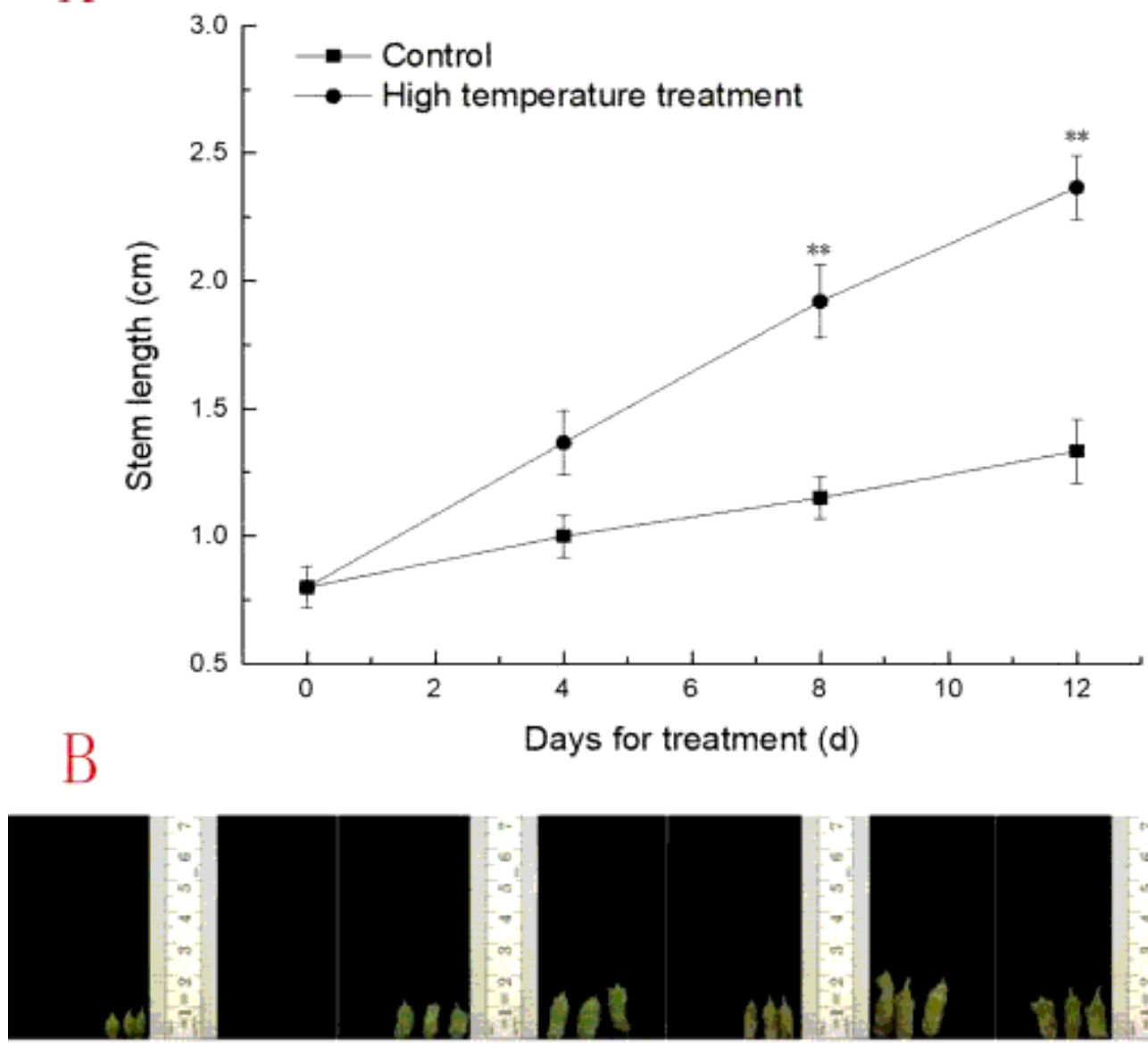

a

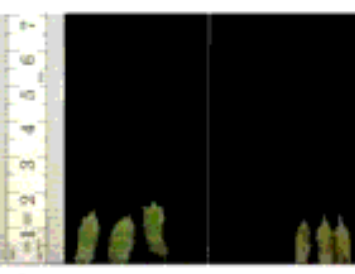

b

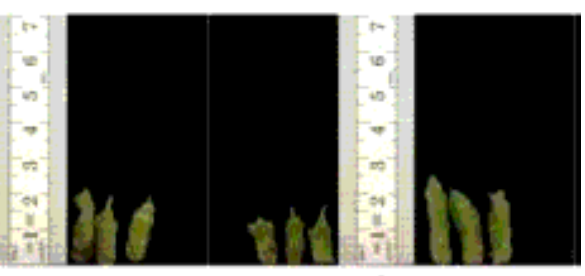

c

d

C
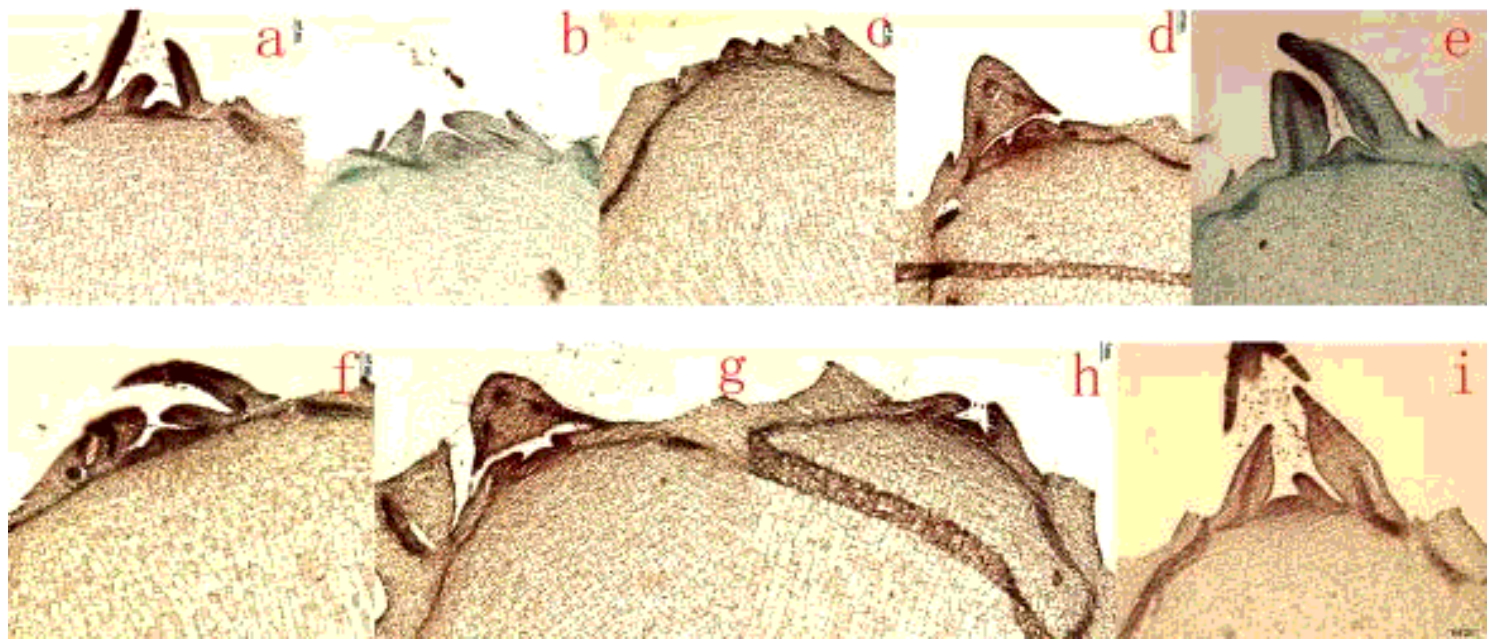

Figure 1

Change of stem height in lettuce after high temperature treatment. (A) Changes of stem length under suitable temperature (control) and high temperature treatment. The data (mean \pm SD) are the means of three replicates with standard errors shown by vertical bars, $n=6$. *and**indicate significant difference at $p<0.05$ and $p<0.01$ by t-test, respectively; (B) The phenotypes of lettuce under different temperature treatments. a, b, c and d represent stem growth after different temperature treatment for 0, 4, 8 and 12 d. 
(control in left and high temperature treatment in right); (C) The progress of flower bud differentiation. a, $b, c, d$ and e represent morphology of flower bud under control temperature for $0,2,4,6$ and $8 \mathrm{~d}, \mathrm{f}, \mathrm{g}, \mathrm{h}$ and i represent morphology of flower bud under high temperature for 2, 4, 6 and $8 \mathrm{~d}$.
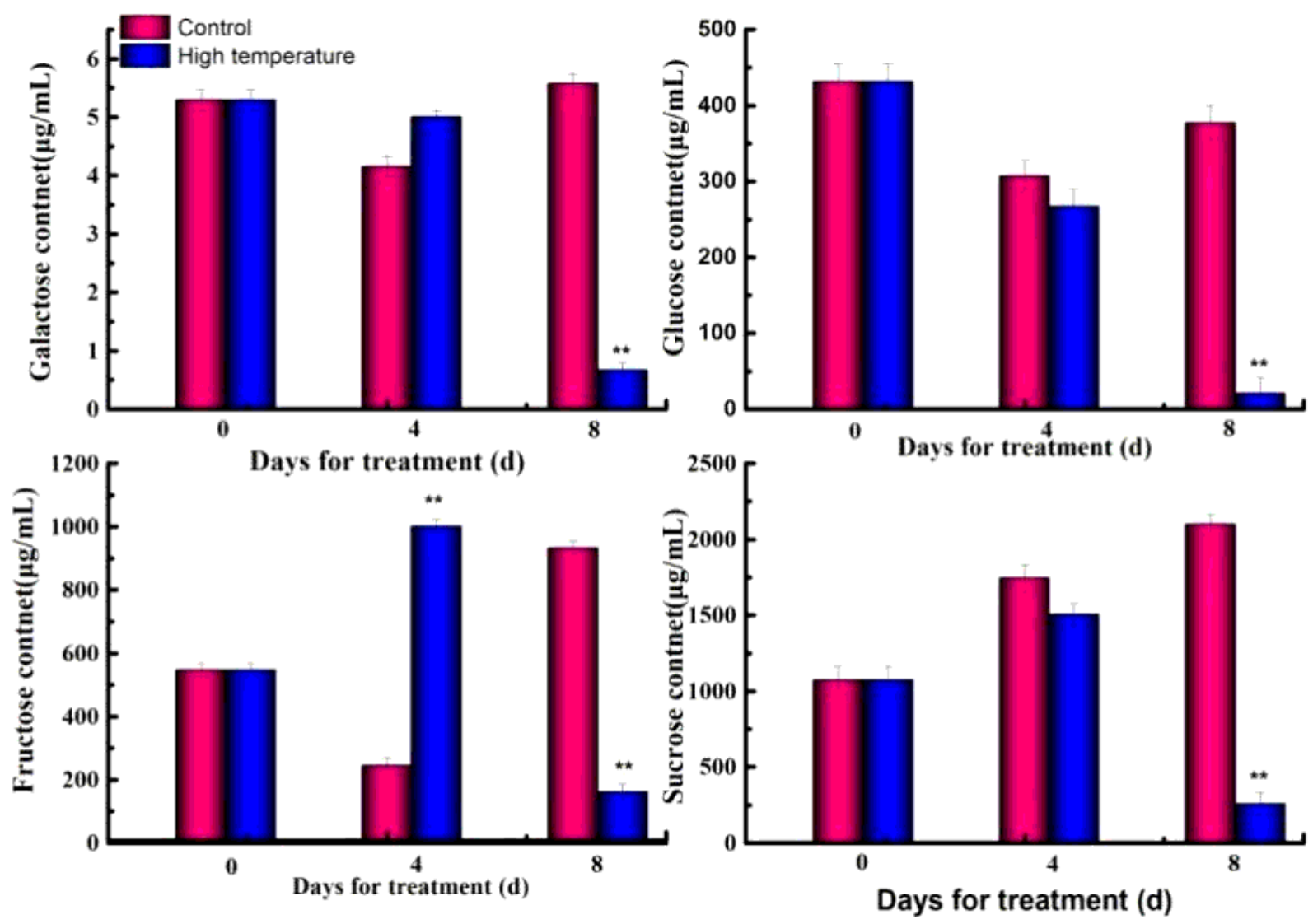

Figure 2

The contents of galactose, glucose, fructose and sucrose of lettuce after high temperature treatment. The data (mean $\pm S D$ ) are the means of three replicates with standard errors shown by vertical bars, $n=3$. *and ${ }^{*}$ indicate significant difference at $p<0.05$ and $p<0.01$ by $t$-test, respectively. 


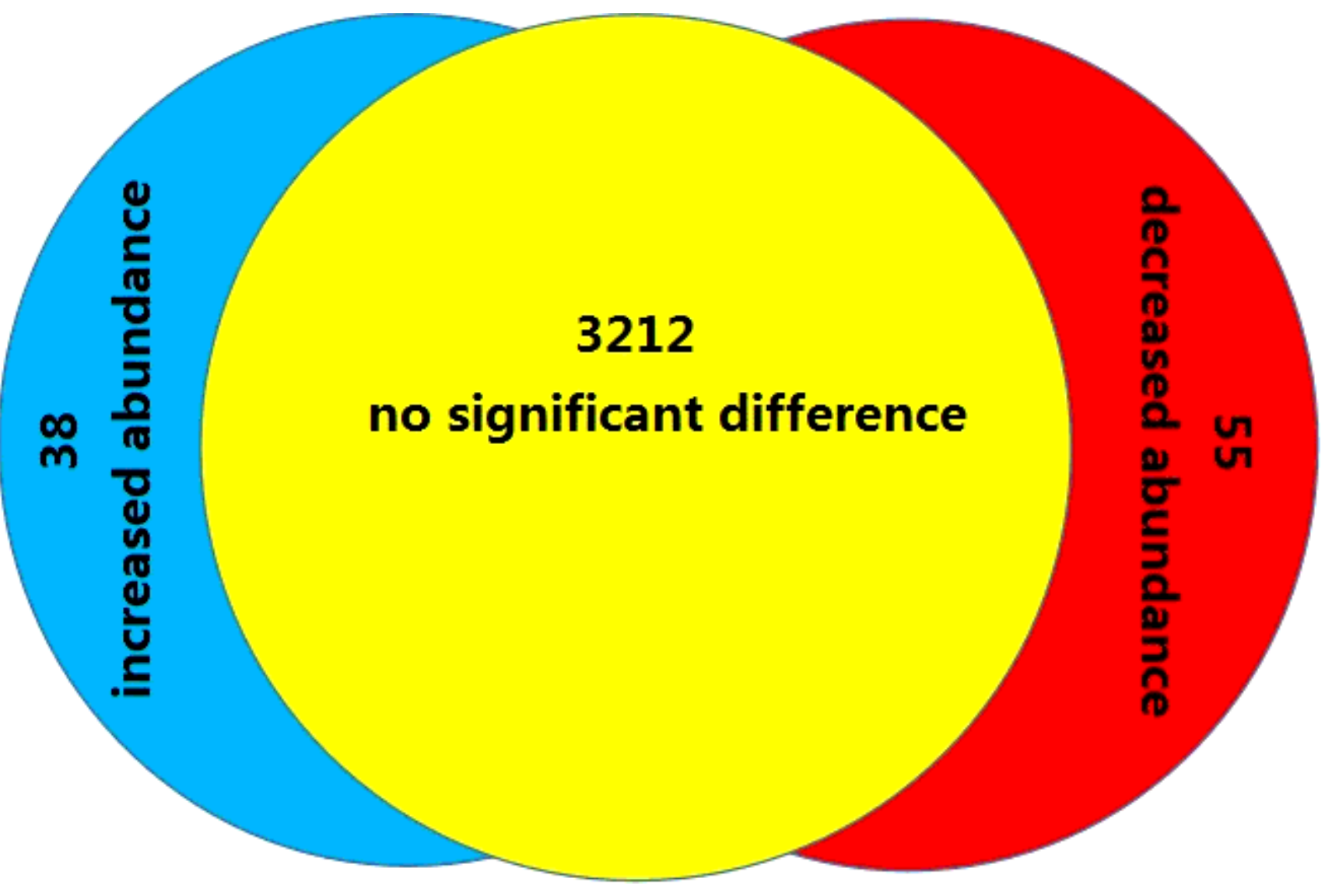

Figure 3

The distribution of differentially expressed proteins. 


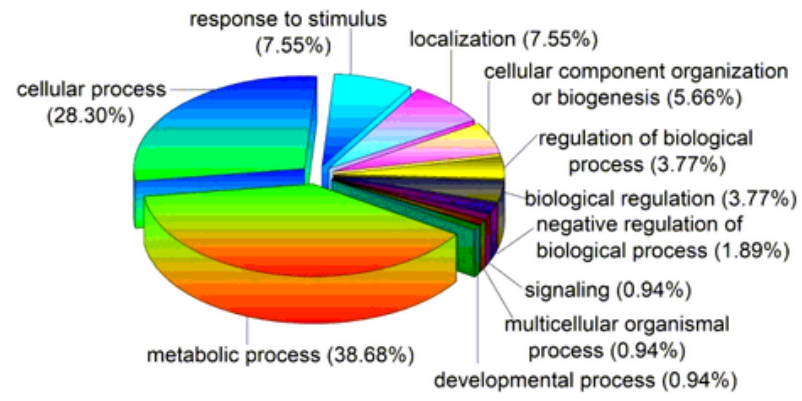

A. Biological Process

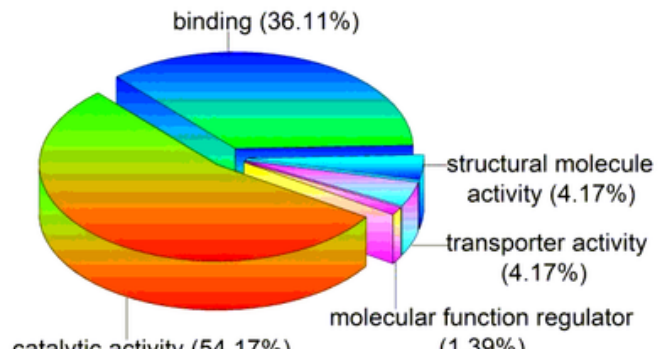

catalytic activity $(54.17 \%) \quad(1.39 \%)$

\section{B. Molecular Function}

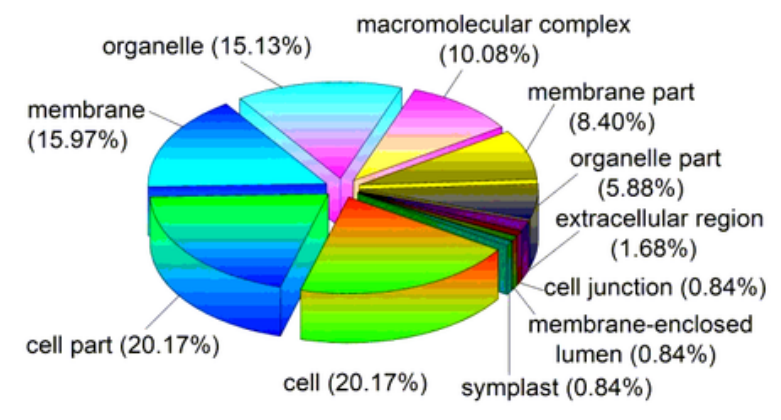

\section{Cellular Component}

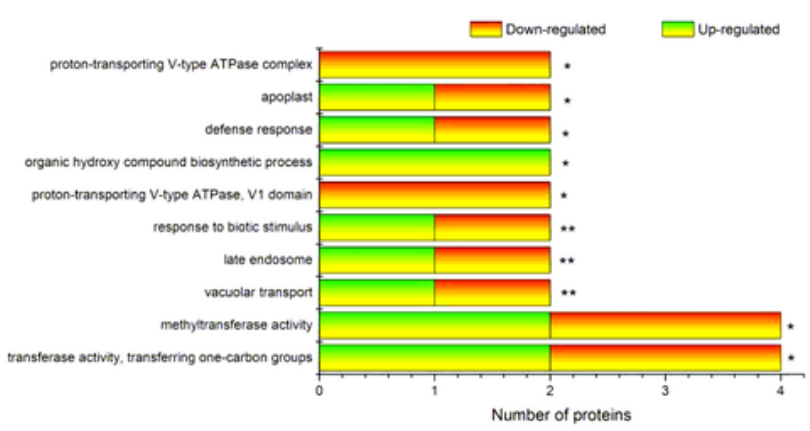

D. GO Enrichment

\section{Figure 4}

ClueGO and GO enrichment analysis of differentially expressed proteins. (A)Biological Process; (B) Molecular Function; (C) Celluclar Component; (D) GO enrichment. * and ** indicate significant difference at $p<0.05$ and $p<0.01$ by t-test, respectively. 


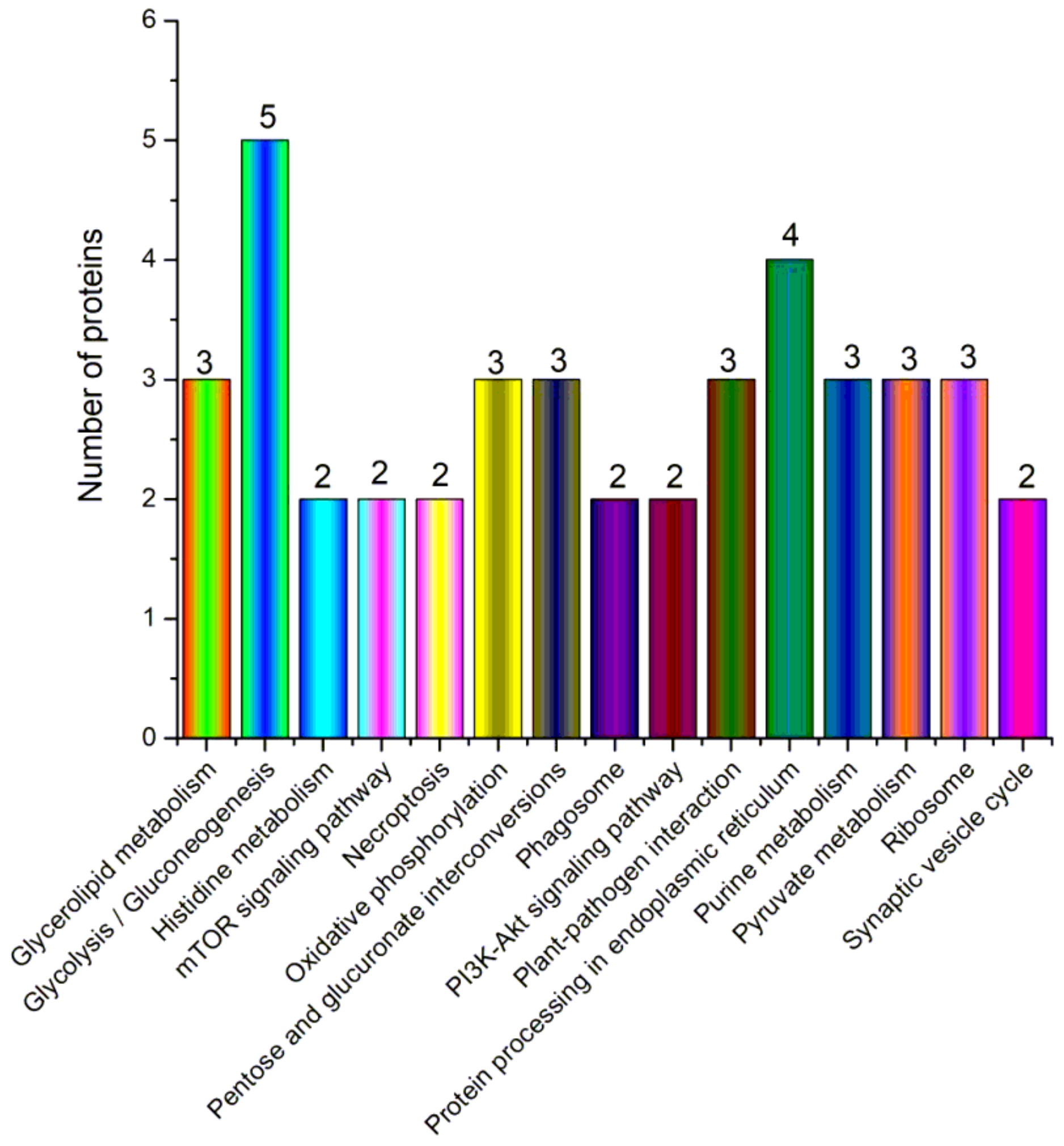

Figure 5

Metabolic analysis of KEGG pathway. 


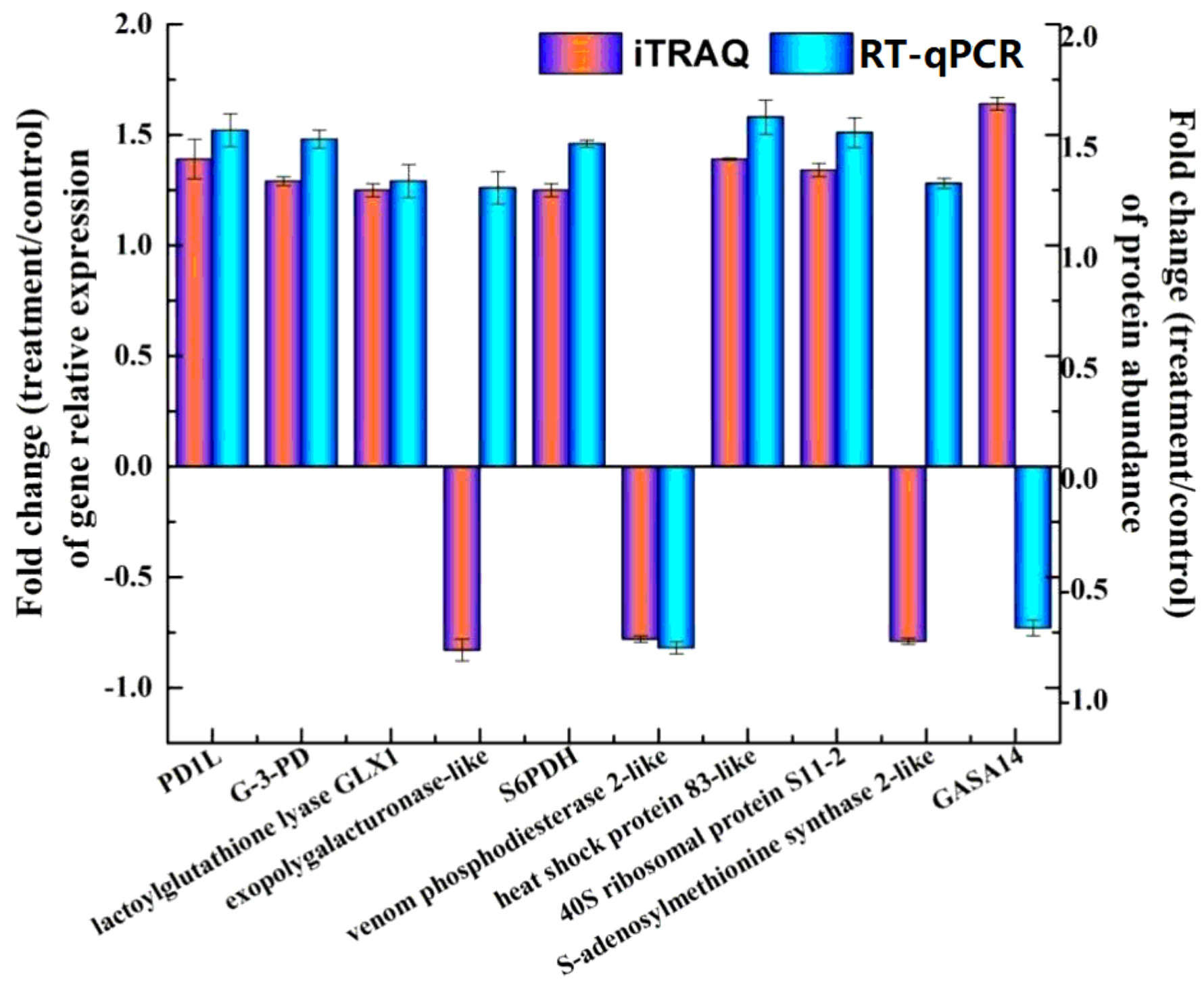

Figure 6

Correlation of mRNA level and protein abundance by iTRAQ. The fold-change of treatment/control in transcript level using the RT-qPCR approach of 10 candidate genes involved in the identified differentially expressed proteins and the protein expression level by ITRAQ is shown in the figure. The positive number indicates up-regulation, and the negative number indicates down regulation. Each histogram represents the mean value of three biological replicates, and the vertical bars indicate the standard error $(n=3)$. Definition of 10 candidate genes involved in the identified differentially expressed proteins: (1) PD1L, pyruvate decarboxylase 1 like; (2) G-3-PD, glyceraldehyde-3-phosphate dehydrogenase; (3) S6PDH, Sorbitol-6-phosphate dehydrogenase; (4) GASA14, Gibberellin-regulated protein 14.

\section{Supplementary Files}

This is a list of supplementary files associated with this preprint. Click to download.

- SupplementaryFigure1.png 
- SupplementaryFigure2.png

- SupplementaryFigure3.png

- SupplementaryFigure4.png

- SupplementaryFigure5.png

- SupplementaryFigure6.png

- TableS1.xIsx

- Tables2.xIsx

- TableS3.xIsx 